\title{
A Successful Multifaceted Trial to Improve Hypertension Control in Primary Care: Why Did it Work?
}

\author{
Karen L. Margolis, M.D., M.P.H. ${ }^{\text {, }}$, Stephen E. Asche, M.A. ${ }^{7}$, Anna R. Bergdall, M.P.H. ${ }^{\text {', }}$ \\ Steven P. Dehmer, Ph.D. ${ }^{7}$, Michael V. Maciosek, Ph.D. ${ }^{\text {, }, ~ R a c h e l ~ A . ~ N y b o e r, ~ B . A . ~}{ }^{7}$, \\ Patrick J. O'Connor, M.D., M.P.H. ' , Pamala A. Pawloski, Pharm.D. ', JoAnn M. Sperl-Hillen, M.DV. ', \\ Nicole K. Trower, B.A. ${ }^{7}$, Ann D. Tucker, B.A. ${ }^{7}$, and Beverly B. Green, M.D., M.P. . $^{2}$ \\ 'HealthPartners Institute for Education and Research, Minneapolis, MN, USA; ²Group Health Research Institute, Seattle, WA, USA.
}

\begin{abstract}
BACKGROUND: It is important to understand which components of successful multifaceted interventions are responsible for study outcomes, since some components may be more important contributors to the intervention effect than others.

OBJECTIVE: We conducted a mediation analysis to determine which of seven factors had the greatest effect on change in systolic blood pressure (BP) after 6 months in a trial to improve hypertension control.

DESIGN: The study was a preplanned secondary analysis of a cluster-randomized clinical trial. Eight clinics in an integrated health system were randomized to provide usual care to their patients $(n=222)$, and eight were randomized to provide a telemonitoring intervention $(n=228)$. PARTICIPANTS: Four hundred three of 450 trial participants completing the 6-month follow-up visit were included.
\end{abstract}

INTERVENTIONS: Intervention group participants received home BP telemonitors and transmitted measurements to pharmacists, who adjusted medications and provided advice to improve adherence to medications and lifestyle modification via telephone visits.

MAIN MEASURES: Path analytic models estimated indirect effects of the seven potential mediators of intervention effect (defined as the difference between the intervention and usual care groups in change in systolic BP from baseline to 6 months). The potential mediators were change in home BP monitor use, number of BP medication classes, adherence to BP medications, physical activity, salt intake, alcohol use, and weight.

KEY RESULTS: The difference in change in systolic BP was $11.3 \mathrm{mmHg}$. The multivariable mediation model explained $47 \%$ (5.3 mmHg) of the intervention effect. Nearly all of this was mediated by two factors: an increase in medication treatment intensity (24\%) and increased home BP monitor use (19\%). The other five factors were not significant mediators, although medication adherence and salt intake improved more in the intervention group than in the usual care group.

CONCLUSIONS: Most of the explained intervention effect was attributable to the combination of self-monitoring and medication intensification. High adherence at baseline and the relatively low intensity of resources directed

Clinical trials registration: clinicaltrials.gov identifier NCTO0781365

Published online May 8, 2015 toward lifestyle change may explain why these factors did not contribute to the improvement in BP.

KEY WORDS: Blood pressure; Hypertension; Randomized trial; Mediation; Telemonitoring; Case management.

J Gen Intern Med 30(11): 1665-72

DOI: $10.1007 / \mathrm{s} 11606-015-3355-\mathrm{x}$

(C) Society of General Internal Medicine 2015

\section{INTRODUCTION}

High blood pressure (BP) is the largest contributor to all-cause and cardiovascular mortality in the United States. ${ }^{1}$ For this reason, recent national initiatives have focused on methods to improve care for the half of individuals with hypertension who do not have BP controlled to recommended levels. ${ }^{2-4} \mathrm{Al}-$ though many types of interventions to improve BP control have been tested over the last several decades, the most potent methods involve a reorganization of clinical practice to include nurses or pharmacists in a team-based approach to hypertension care. ${ }^{5-9}$ Home BP monitoring has also been found to be a useful adjunct to team-based care for hypertension. ${ }^{10}$

We have reported the main results of a cluster-randomized trial that compared usual care to an intervention combining home BP telemonitoring and pharmacist management. ${ }^{11}$ At 6 months of follow-up, $72 \%$ of participants in the intervention group had achieved BP control, compared with $45 \%$ in the usual care group $(p<0.001)$. The intervention group also had greater lowering of systolic BP (SBP) by $11.3 \mathrm{mmHg}$ and diastolic BP (DBP) by $5.8 \mathrm{mmHg}$, and the improvement in BP persisted through 18 months of follow-up.

Potential mechanisms contributing to the better BP outcomes in the intervention group included greater medication intensification, improved adherence to pharmacologic treatment and lifestyle modification, and greater patient and pharmacist acceptance that BP was truly elevated as evidenced by home monitoring. Some components of multifaceted interventions may contribute more significantly to achieving the study outcomes than others. Understanding the key mediators of the intervention effect is important in implementing successful interventions, since ineffective components can be de- 
emphasized to direct more resources toward effective components. Therefore, we conducted a planned mediation analysis to determine the factors that were the largest contributors to the blood pressure improvements we observed in the trial.

\section{METHODS}

\section{Design, Setting, and Patients}

The study was a two-group cluster-randomized clinical trial conducted at HealthPartners Medical Group, a multispecialty practice in the Minneapolis-St. Paul metropolitan area that is part of an integrated health system. ${ }^{12}$ All participants provided informed consent, and the study protocol was approved by the HealthPartners Institutional Review Board.

We used electronic data to identify and contact by mail and telephone 14,492 adult patients who had BP readings $\geq 140$ / $90 \mathrm{mmHg}$ at their two most recent primary care encounters within the previous year. Study participants were further required to have uncontrolled BP $(>140 / 90 \mathrm{mmHg}$ or $>130 /$ $80 \mathrm{mmHg}$ if diabetes or kidney disease was present $)^{13}$ based on the average of three automated measurements taken in the research clinic using a standardized protocol. ${ }^{12}$ Medical exclusion criteria included stage 4 or 5 kidney disease or an albumin-to-creatinine ratio $>700 \mathrm{mg} / \mathrm{g}$ creatinine; acute coronary syndrome, coronary revascularization, or stroke within the past 3 months; known secondary causes of hypertension; pregnancy; and New York Heart Association class III or IV heart failure or known left ventricular ejection fraction $<30 \%$. Of 2020 patients who were screened for the study, 450 were eligible and agreed to participate.

Among the 21 HealthPartners primary care clinics in 2009, 16 had a medication therapy management (MTM) pharmacist on-site at least once weekly. ${ }^{14}$ At these clinics there was a clinical practice agreement between pharmacists and primary care physicians that allowed pharmacists to prescribe and change antihypertensive therapy within specified parameters. The 16 study clinics were randomly assigned to either the Telemonitoring Intervention (TI, $n=8$ ) or Usual Care (UC, $n=8$ ) groups. Four doctoral pharmacists worked in TI clinics. Patients were linked to their clinic by self-report and assigned a treatment accordingly. All consenting patients and pharmacists were blinded before randomization, but were informed of their treatment assignment post-randomization.

\section{Interventions}

Intervention patients received home monitors (A\&D Medical UA-767PC automatic oscillometric BP monitor; A\&D Engineering, Inc., San Jose, CA, USA) that stored and transmitted BP data to a secure website via a modem (AMC Health, New York, NY, USA). Pharmacists met with patients for a 1-hour in-person visit during which they reviewed the patient's relevant history, covered general teaching points about hypertension, and instructed patients on the use of the home BP telemonitor system and the individualized home BP goal (i.e., $<135 / 85$, or $<125 / 75 \mathrm{mmHg}$ for patients with diabetes or kidney disease). ${ }^{15,16}$ Patients were instructed to transmit at least six BP measurements weekly (three in the morning and three in the evening). During the first 6 months of intervention, which is the time period covered in these analyses, patients and pharmacists met every 2 weeks via phone until BP control was sustained for 6 weeks, and the frequency was then reduced to monthly. During intervention months 7-12, phone visits occurred every 2 months. After 12 months, patients returned the telemonitors, returned to their primary physicians' care, and received no pharmacist support. A previous analysis had found that patients sent at least six BP measurements per week $73 \%$ of the time during the first 6 months of the intervention and that $88 \%$ of expected phone visits were conducted. ${ }^{17}$

During phone visits, pharmacists emphasized lifestyle changes and medication adherence. They assessed and adjusted antihypertensive drug therapy based on an algorithm using the percentage of home BP readings meeting goal. ${ }^{12}$ Generally, if at least $75 \%$ of readings since the last visit met the BP goal, no medication changes were suggested. If fewer than $75 \%$ of readings met goal, the algorithm recommended treatment intensification. Regardless of BP control, if patients experienced adverse effects, the drug dosage could be lowered or the drug changed. Following each visit, pharmacists communicated with patients' primary care teams through the electronic medical record.

During the study period, Usual Care patients worked with their primary care physicians as usual. This could include referral to an MTM pharmacist for consultation (1-2 visits without telephone follow-up or prolonged monitoring) and conventional home BP measurement.

\section{Measures}

Baseline characteristics were gathered through measurements (weight, BP) and a survey (demographics, potential mediators) at the baseline clinic visit. All measurements were repeated at the 6-month clinic visit. At each visit, BP was computed as the mean of three measurements using a standardized technique with an automatic oscillometric monitor (A\&D Medical UA767PC). The primary outcome for the mediation analysis was change in SBP between the baseline and 6-month clinic visits. We defined intervention effect as the difference between the intervention and usual care groups in change in systolic BP from baseline to 6 months.

A total of seven potential mediator variables were selected a priori on the basis of prior research and plausible mechanistic pathway: home BP monitor use, number of BP medication classes, patient-reported adherence to BP medications, physical activity, salt intake, alcohol use, and weight change. ${ }^{6,10,13,18}$ Use of a home BP monitor was coded as follows: $0=$ "none," 1 = "less than once per er month," $2=$ "a few times per month," and 3 = "once a week or more." BP 
medication class counts were gathered using medication inventories at baseline and follow-up, and ranged from 0 to 6 . Self-reported adherence to BP medications was calculated as the sum of four items indicating non-adherence, and could range from 0 (good adherence) to 4 (poor adherence).$^{19}$ Physical activity was coded as the number of times per week over the past 4 weeks that a respondent engaged in either moderate physical activity for $30 \mathrm{~min}$ or more or vigorous physical activity for $20 \mathrm{~min}$ or more (range $0-14$ ). Salt intake was measured as the sum of two items: the frequency of adding salt to food after it was served and the frequency of adding salt during food preparation (range 0-6). Response categories for these items were $0=$ "rarely," $1=$ "several times per week," 2 = "about once a day," and 3 = "with almost all meals." Alcohol use was measured as the number of alcoholic drinks consumed each week, with codes of $0=$ "none," $1=$ " $2-3$," 2 $=" 4-6, " 3=" 7-12$, and " $4=">12$." Weight was measured in pounds at both visits. The categorical coding of home BP monitor use, medication adherence, salt intake, and alcohol use reflected the response options used in the surveys.

In order to capture both newly added medication and dose changes, we conducted a sensitivity analysis using defined daily dose (DDD) instead of the BP medication class count. Each medication was converted to a DDD based on methods developed by the World Health Organization. ${ }^{20,21}$ Treatment intensity for each participant at each medication inventory time point was calculated as the sum of the DDD for all antihypertensive medications (range $0-13.2$ at baseline).

The seven potential mediator variables were measured again at 6 months using the same scale for each item. Mediators used in the analysis are all expressed as a change score from baseline to the 6-month measurement. For example, a patient not using a home BP monitor at baseline $($ score $=0$ ) but who was doing so a few times a month at the 6-month visit (score $=2$ ) would have a mediator change score of $2-0=2$. Change scores for all other mediators were computed in the same way. Negative change scores represented improved adherence to BP medications (possible range -4 to 4 ), reduced salt intake (possible range -6 to 6 ), reduced alcohol intake (possible range -4 to 4 ), and reduced weight. Positive change scores represent increased home BP monitor use (possible range -3 to 3 ), increased number of BP medication classes prescribed (actual range -2 to 4 ), increased DDD (actual range -4.0 to 7.3 ), and increased physical activity (possible range -14 to 14$)$. The change scores were used for the analysis due to existing differences at baseline in some of the mediators.

\section{Statistical Analysis}

Baseline measurements are described using percentages, means, and standard deviations. Baseline differences by study treatment group were examined in contingency tables and tested using Pearson's $\chi^{2}$ or independent samples $t$ tests. Path analytic models ${ }^{22-24}$ were used to test single-mediator models, in which a binary indicator for study treatment group predicted a potential mediator change score (path a) and the mediator change score predicted change in SBP (path b, Fig. 1a). The product of paths $(\mathrm{ab})$ represents the specific indirect effect for a mediator, and is referred to as the mediated effect. The total unmediated effect of the intervention is path c (Fig. 1b, when no mediators are included in the model), in this case the between-group differences in change in SBP from the baseline clinic visit to the 6-month clinic visit, which was $11.3 \mathrm{mmHg}$. The study treatment group indicator predicted change in SBP not explained by the mediated path ab is path c'. The proportion of the total effect of the intervention due to mediating effects is computed as (c-c')/c. A path analytic multiplemediation model utilized all seven potential mediators, each with a path from the study treatment group variable to the mediator (paths $\mathrm{a}_{1-7}$ ) and from the mediator to change in SBP (paths $b_{1-7}$ ) (Fig. 2).

Path analytic models were estimated using Mplus $v 7^{24}$ with full information maximum likelihood estimation to obtain regression coefficients, standard errors, and specific indirect effects (mediated effects) representing the product of the $a \cdot b$ path coefficients and their standard errors. Mediation by a specific variable was deemed significant when its specific indirect effect (ab) was significant at $p<0.05$.

\section{RESULTS}

The analytic sample consists of 403 (206 TI, 197 UC) of the 450 trial participants who completed the 6-month research clinic visit. At entry, the mean age was 61 years, $43 \%$ of the participants were female, and $83 \%$ were non-Hispanic white (Table 1). Half of the participants had a 4-year college degree, and $41 \%$ were working full-time. The mean BP was 148/ $85 \mathrm{mmHg}$. About half (46\%) of the participants had used a home BP monitor in the past year, and the mean number of BP medication classes was 1.5. Self-reported medication adherence was high, with $67 \%$ reporting good adherence. Participants reported moderate or vigorous-intensity physical activity 3.9 times per week, one-third added salt daily to food served at the table or food they prepared, and $21 \%$ consumed seven or more alcoholic beverages per week. Most baseline characteristics were balanced between treatment groups; however, TI group participants used home BP monitoring more frequently than UC group participants ( $25 \%$ weekly or more for TI vs. $13 \%$ for UC, $p=0.02$ ), and they had a higher mean count of antihypertensive medication classes (1.7 TI vs. $1.4 \mathrm{UC}$, $p=0.03$ ). The mean (SD) reduction in SBP from baseline to the 6-month visit was $-21.6(15.9) \mathrm{mmHg}$ in TI patients and $-10.3(16.7)$ in UC patients $(p<0.001)$. Thus, the total effect of the intervention on change in SBP (path c) without mediating effects was $-11.3(1.62) \mathrm{mm} \mathrm{Hg}$. Table 1 also shows the calculated mean scores at baseline for home BP monitor use, medication adherence, salt intake, and alcohol use.

At the 6-month follow-up, the TI group had significantly larger increases than the UC group in home BP monitor use 


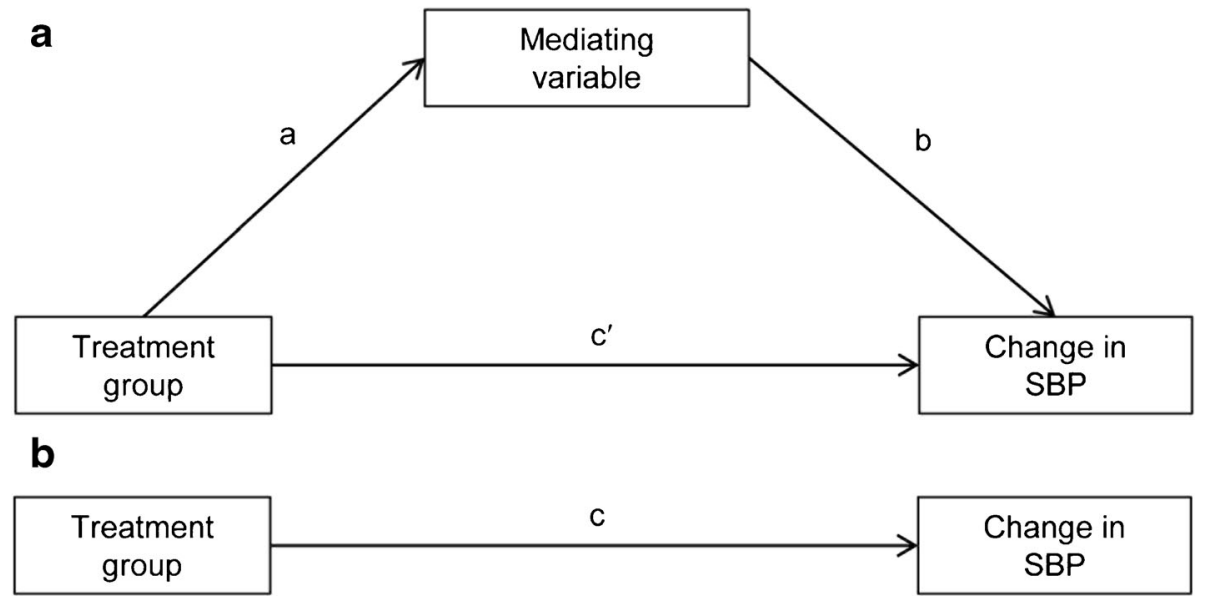

Fig. 1 a Single-mediator model. b Unmediated treatment effect

score, number of antihypertensive drug classes, and adherence to BP medications, and they added salt to food less often (Table 2). Physical activity, alcohol use, and weight change did not differ between TI and UC groups.

Among the seven mediators tested, change in home BP monitor use and change in count of BP medication classes had statistically significant mediated effects (path $a \cdot b$ ) in single- and multiple-mediator models (Table 3). For example, in the single-mediator model, the intervention group was associated with a 0.50 unit increase in the count of BP medication classes from baseline to follow-up. Each unit increase in BP medication classes was associated with a reduction of $5.64 \mathrm{mmHg}$ SBP, and the mediated effect $(\mathrm{a} \cdot \mathrm{b})$ of the intervention was to reduce SBP by $2.83 \mathrm{mmHg}$ through the increased number of BP medication classes. The mediated effect of the intervention through medication intensification accounted for $25.0 \%$ of the total effect of the intervention on change in SBP.

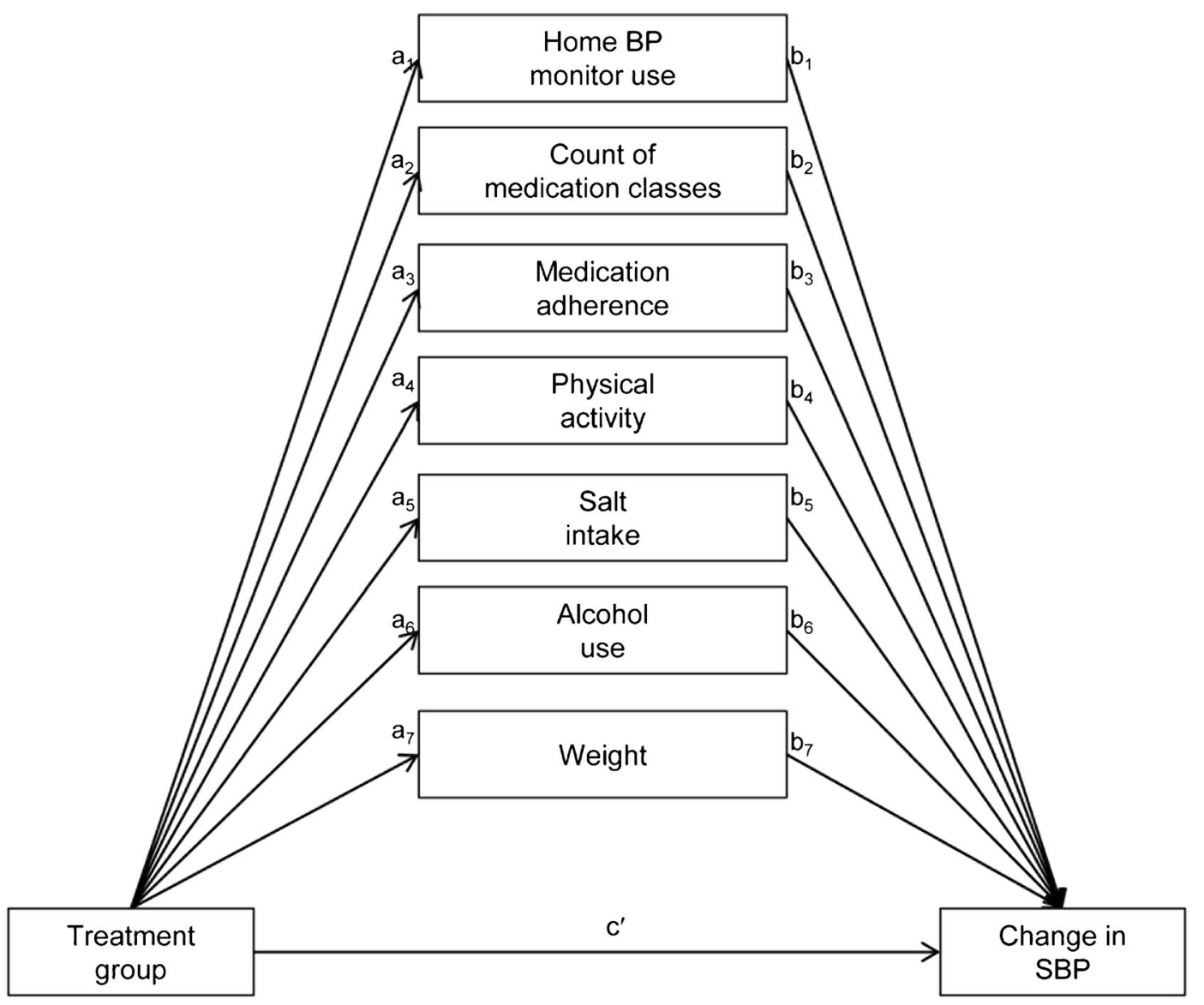

Fig. 2 Multiple-mediator model 
Table 1 Patient Characteristics and Proposed Mediators at the Baseline Visit

\begin{tabular}{|c|c|c|c|}
\hline & $\begin{array}{l}\text { Telemonitoring } \\
\text { intervention } \\
(n=206)\end{array}$ & $\begin{array}{l}\text { Usual care } \\
(n=197)\end{array}$ & $\mathbf{p}$ \\
\hline \multicolumn{4}{|l|}{ Baseline characteristics } \\
\hline Age, mean (SD), years & $62.3(11.4)$ & $60.2(12.1)$ & 0.09 \\
\hline Female $(\%)$ & $88(42.7 \%)$ & $86(43.7 \%)$ & 0.85 \\
\hline Non-Hispanic white (\%) & $176(85.4 \%)$ & $159(80.7 \%)$ & 0.27 \\
\hline Education $(\%)$ & & & 0.76 \\
\hline$\leq$ High school/GED & $31(15.5 \%)$ & $33(17.1 \%)$ & \\
\hline Some college or tech school & $64(32.0 \%)$ & $69(35.8 \%)$ & \\
\hline 4-Year college degree & $43(21.5 \%)$ & $36(18.7 \%)$ & \\
\hline$>4$-Year college degree & $62(31.0 \%)$ & $55(28.5 \%)$ & \\
\hline Employment $(\%)$ & & & 0.61 \\
\hline Full-time & $80(40.0 \%)$ & $82(42.5 \%)$ & \\
\hline Part-time & $26(13.0 \%)$ & $20(10.4 \%)$ & \\
\hline Not working & $15(7.5 \%)$ & $20(10.4 \%)$ & \\
\hline Retired & $79(39.5 \%)$ & $71(36.8 \%)$ & \\
\hline Systolic blood pressure, mean (SD), mmHg & $148.3(12.6)$ & $146.8(12.3)$ & 0.24 \\
\hline Diastolic blood pressure, mean (SD), $\mathrm{mmHg}$ & $84.0(11.9)$ & $84.9(11.2)$ & 0.46 \\
\hline \multicolumn{4}{|l|}{ Home BP monitor use past year } \\
\hline None & $99(49.5 \%)$ & $110(57.9 \%)$ & 0.02 \\
\hline$<$ once per month & $22(11.0 \%)$ & $29(15.3 \%)$ & \\
\hline A few times per month & $30(15.0 \%)$ & $27(14.2 \%)$ & \\
\hline Once a week or more & $49(24.5 \%)$ & $24(12.6 \%)$ & \\
\hline Home BP monitor use score, mean $(\mathrm{SD})^{\mathrm{a}}$ & $1.15(1.27)$ & $0.81(1.09)$ & 0.007 \\
\hline Number of antihypertensive drug classes, mean (SD) & $1.7(1.33)$ & $1.4(1.22)$ & 0.03 \\
\hline Good self-reported hypertension medication adherence $(\%$ score $=0)$ & $103(67.3 \%)$ & $85(65.9 \%)$ & 0.80 \\
\hline Patient-reported medication adherence score, mean (SD) ${ }^{\mathrm{b}}$ & $0.46(0.79)$ & $0.54(0.89)$ & 0.44 \\
\hline $\begin{array}{l}\text { Number of times per week in the past } 4 \text { weeks with moderate } \\
\text { or vigorous physical activity, mean (SD) }{ }^{\mathrm{c}}\end{array}$ & $3.9(3.15)$ & $4.0(3.23)$ & 0.73 \\
\hline Adds salt daily to served food or when preparing food $(\%)$ & $73(36.0 \%)$ & $62(31.6 \%)$ & 0.36 \\
\hline Salt intake score, mean (SD) ${ }^{\mathrm{d}}$ & $1.4(1.72)$ & $1.5(1.71)$ & 0.35 \\
\hline$\geq 7$ alcohol drinks per week $(\%)$ & $44(21.6 \%)$ & $39(20.1 \%)$ & 0.72 \\
\hline $\bar{A}$ lcohol use score, mean (SD) & $1.4(1.13)$ & $1.4(1.13)$ & 0.85 \\
\hline Weight, lbs, mean (SD) & $203.2(50.9)$ & $205.9(44.2)$ & 0.57 \\
\hline
\end{tabular}

"Home BP monitor use in past year, $0=$ "none," $1=$ "< once per month," $2=$ "a few times per month," $3=$ "once a week or more"

${ }^{b}$ Sum of four binary items indicating non-adherence, range 0 (good adherence) to 4 (poor adherence)

${ }^{c}$ Number of times per week over the past 4 weeks with moderate or vigorous physical activity, range 0-14

${ }^{d}$ Sum of two items: frequency of adding salt to food after it is served and when preparing food. Items scored as $0=$ "rarely," $1=$ "several times per week," 2 = "about once a day," 3 = "with almost all meals." Salt score range $0-6$

"Number of drinks with alcohol consumed each week, "0" = "none," $1=" \leq 3$," $2=" 4-6$," $3=" 7-12$," $4=$ " $>12$ "

Table 2 Changes in Potential Mediator Variables from Baseline to 6-Month Visit

\begin{tabular}{|c|c|c|c|}
\hline Potential mediators* & $\begin{array}{l}\text { Telemonitoring } \\
\text { intervention } \\
(n=206)\end{array}$ & $\begin{array}{l}\text { Usual } \\
\text { care } \\
(n=197)\end{array}$ & $\mathbf{p}$ \\
\hline $\begin{array}{l}\text { Change in home BP } \\
\text { monitor use score, } \\
\text { mean (SD) }\end{array}$ & +1.55 (1.39) & $\begin{array}{l}+0.11 \\
(0.89)\end{array}$ & $<0.001$ \\
\hline $\begin{array}{l}\text { Change in number of } \\
\text { antihypertensive drug } \\
\text { classes, mean (SD) }\end{array}$ & $+0.68(0.91)$ & $\begin{array}{l}+0.18 \\
(0.68)\end{array}$ & $<0.001$ \\
\hline $\begin{array}{l}\text { Change in patient- } \\
\text { reported } \\
\text { adherence to hypertension } \\
\text { medications score, } \\
\text { mean (SD) }\end{array}$ & $-0.20(0.85)$ & $\begin{array}{l}+0.07 \\
(0.83)\end{array}$ & 0.01 \\
\hline $\begin{array}{l}\text { Change in physical } \\
\text { activity score, mean (SD) }\end{array}$ & +0.57 (2.99) & $\begin{array}{l}+0.11 \\
(2.70)\end{array}$ & 0.11 \\
\hline $\begin{array}{l}\text { Change in salt intake } \\
\text { score, mean (SD) }\end{array}$ & $-0.56(1.22)$ & $\begin{array}{l}-0.07 \\
(1.36)\end{array}$ & $<0.001$ \\
\hline $\begin{array}{l}\text { Change in alcohol use } \\
\text { score, mean (SD) }\end{array}$ & $-0.14(0.66)$ & $\begin{array}{l}-0.06 \\
(0.57)\end{array}$ & 0.20 \\
\hline $\begin{array}{l}\text { Change in weight, lbs, } \\
\text { mean (SD) }\end{array}$ & $+0.27(10.4)$ & $\begin{array}{l}+0.38 \\
(11.9)\end{array}$ & 0.93 \\
\hline
\end{tabular}

*Computed as the 6-month measurement minus the baseline measurement
In the multiple-mediator model, the mediated effect $(a \cdot b)$ of the intervention was to reduce SBP by $2.67 \mathrm{mmHg}$ through the increased number of BP medication classes. Similarly, the intervention group was associated with a 1.44-unit increase in the home BP monitor use variable from baseline to followup. Each unit increase in the home BP monitor use variable was associated with a reduction of $1.47 \mathrm{mmHg} \mathrm{SBP}$, and the mediated effect $(a \cdot b)$ of the intervention was to reduce SBP by $2.12 \mathrm{mmHg}$ through the increased use of home BP monitoring. The mediated effect of the intervention through these two variables accounted for $42.3 \%$ of the total effect of the intervention on change in SBP. Change in patient-reported adherence to BP medications, physical activity, salt intake, alcohol use, and weight did not have significant mediating effects (specific indirect effects, $a \cdot b$ ) on change in SBP, even though medication adherence and salt intake improved in the intervention group (path a). When the five non-significant mediating paths were added, the mediated effect through all seven variables accounted for $46.6 \%(5.3 \mathrm{mmHg})$ of the total $11.3 \mathrm{mmHg}$ effect of the intervention on change in SBP, while $53.4 \%(6 \mathrm{mmHg})$ of the intervention effect remained unexplained by the mediators we examined. 
Table 3 Coefficients and Specific Indirect Effects in Path Models Predicting Change in Systolic Blood Pressure (SBP) from the Intervention and Proposed Mediating Variables

\begin{tabular}{|c|c|c|c|c|}
\hline $\begin{array}{l}\text { Mediator (change from } \\
\text { baseline to } 6 \text { months) }\end{array}$ & $\begin{array}{l}\text { Intervention effect } \\
\text { on mediator } \\
\text { Path a (SE) }\end{array}$ & $\begin{array}{l}\text { Mediator effect on change } \\
\text { in SBP in } \mathrm{mm} \mathrm{Hg} \text { from } \\
\text { baseline to } 6 \text { months } \\
\text { Path b (SE) }\end{array}$ & $\begin{array}{l}\text { Mediated effect } \\
\text { in } \mathrm{mm} \mathrm{Hg} \\
\mathrm{a} \cdot \mathrm{b}(\mathrm{SE})\end{array}$ & $\begin{array}{l}\text { Proportion of total effect } \\
\text { due to mediated effect } \\
(c-c ') / c\end{array}$ \\
\hline \multicolumn{5}{|c|}{ Single-mediator models using mediator change scores from baseline to 6 months } \\
\hline Home BP monitor use & $\begin{array}{l}1.44 * * * \\
(0.12)\end{array}$ & $\begin{array}{l}-2.21^{* *} \\
(0.72)\end{array}$ & $\begin{array}{l}-3.18^{* *} \\
(1.07)\end{array}$ & $28.1 \%$ \\
\hline Count of BP medication classes & $\begin{array}{l}0.50 * * * \\
(0.08)\end{array}$ & $\begin{array}{l}-5.64 * * * \\
(0.93)\end{array}$ & $\begin{array}{l}-2.83 * * * \\
(0.66)\end{array}$ & $25.0 \%$ \\
\hline Patient-reported medication adherence & $\begin{array}{l}-0.27 * * \\
(0.10)\end{array}$ & $\begin{array}{l}0.88 \\
(1.15)\end{array}$ & $\begin{array}{l}-0.24 \\
(0.33)\end{array}$ & $2.1 \%$ \\
\hline Physical activity & $\begin{array}{l}0.46 \\
(0.29)\end{array}$ & $\begin{array}{l}-0.41 \\
(0.29)\end{array}$ & $\begin{array}{l}-0.19 \\
(0.18)\end{array}$ & $1.7 \%$ \\
\hline Salt intake & $\begin{array}{l}-0.49^{* * *} \\
(0.13)\end{array}$ & $\begin{array}{l}0.37 \\
(0.64)\end{array}$ & $\begin{array}{l}-0.18 \\
(0.31)\end{array}$ & $1.6 \%$ \\
\hline Alcohol use & $\begin{array}{l}-0.08 \\
(0.06)\end{array}$ & $\begin{array}{l}0.68 \\
(1.32)\end{array}$ & $\begin{array}{l}-0.06 \\
(0.11)\end{array}$ & $0.5 \%$ \\
\hline Change in weight & $\begin{array}{l}-0.12 \\
(1.11)\end{array}$ & $\begin{array}{l}0.15^{*} \\
(0.07)\end{array}$ & $\begin{array}{l}-0.02 \\
(0.17)\end{array}$ & $0.2 \%$ \\
\hline \multicolumn{5}{|c|}{ Multiple-mediator model using mediator change scores from baseline to 6 months } \\
\hline Home BP monitor use & $\begin{array}{l}1.44 * * * \\
(0.12)\end{array}$ & $\begin{array}{l}-1.47^{*} \\
(0.70)\end{array}$ & $\begin{array}{l}-2.12^{*} \\
(1.02)\end{array}$ & $18.7 \%$ \\
\hline Count of BP medication classes & $\begin{array}{l}0.50^{* * * *} \\
(0.08)\end{array}$ & $\begin{array}{l}-5.32 * * * \\
(0.93)\end{array}$ & $\begin{array}{l}-2.67 * * * \\
(0.64)\end{array}$ & $23.6 \%$ \\
\hline Patient-reported medication adherence & $\begin{array}{l}-0.27 * * \\
(0.10)\end{array}$ & $\begin{array}{l}0.27 \\
(1.09)\end{array}$ & $\begin{array}{l}-0.07 \\
(0.30)\end{array}$ & $0.6 \%$ \\
\hline Physical activity & $\begin{array}{l}0.46 \\
(0.29)\end{array}$ & $\begin{array}{l}-0.31 \\
(0.27)\end{array}$ & $\begin{array}{l}-0.14 \\
(0.15)\end{array}$ & $1.2 \%$ \\
\hline Salt intake & $\begin{array}{l}-0.49^{* * *} \\
(0.13)\end{array}$ & $\begin{array}{l}0.41 \\
(0.61)\end{array}$ & $\begin{array}{l}-0.20 \\
(0.30)\end{array}$ & $1.8 \%$ \\
\hline Alcohol use & $\begin{array}{l}-0.08 \\
(0.06)\end{array}$ & $\begin{array}{l}0.57 \\
(1.25)\end{array}$ & $\begin{array}{l}-0.05 \\
(0.11)\end{array}$ & $0.4 \%$ \\
\hline Change in weight & $\begin{array}{l}-0.12 \\
(1.11)\end{array}$ & $\begin{array}{l}0.16^{*} \\
(0.07)\end{array}$ & $\begin{array}{l}-0.02 \\
(0.18)\end{array}$ & $0.2 \%$ \\
\hline All 7 mediators in model & & & & $46.6 \%$ \\
\hline
\end{tabular}

$* p<0 ., 05 * * p<0.01, * * * p<0.001$

In the sensitivity analysis using defined daily dose (DDD) in place of the count of BP medication classes, the mean DDD at baseline was $2.3(\mathrm{SD}=2.36)$ in the intervention group and 1.8 $(\mathrm{SD}=2.01)$ in usual care $(\mathrm{p}=0.05)$. The mean DDD change between baseline and 6 months was $+1.20(\mathrm{SD}=1.67)$ in intervention and $+0.32(\mathrm{SD}=1.22)$ in usual care $(p<0.001)$. The mediated effect for DDD was slightly smaller than the mediated effect for BP medication classes in both the single-mediator model ( $a \cdot b=2.44 \mathrm{mmHg}$ for DDD, $a \cdot b=2.83 \mathrm{mmHg}$ for BP medication class count $)$ and multiple-mediator model $(\mathrm{a} \cdot \mathrm{b}=2.30 \mathrm{mmHg}$ for DDD, $a \cdot b=2.67 \mathrm{mmHg}$ for BP medication class count).

\section{DISCUSSION}

The analyses described above account for almost half (47 \%) of the difference in SBP between the TI and UC groups in this multifaceted interventional study. Specifically, the increase in home BP monitoring and medication intensification were both significant mediators, and together accounted for nearly all (42\%) of the intervention effect explained by the potential mediators we examined. Even though the intervention appeared to improve self-reported medication adherence and salt intake, these factors contributed little to the intervention effect. Several other lifestyle factors (physical activity, alcohol use, and weight) were not affected by the intervention. and therefore did not have significant specific indirect effects.

Our results are quite similar to those reported by Ralston et al. in their analysis of mediation effects of another pharmacist-led intervention to improve BP using electronic messaging. ${ }^{18,25}$ That study likewise found that increased frequency of home BP monitoring, interactions with pharmacists, and medication intensification were mediators of the improved blood pressure control observed in the intervention group, while adherence and lifestyle changes were not. It is not surprising that both studies found that increased selfmonitoring and medication intensification were the major mediators of the intervention effect, since these were key components of the intervention. In the present study, all participants in the intervention group were given a home BP telemonitor, and $94 \%$ reported using a monitor at the 6month follow-up. ${ }^{11}$ Although home BP monitor use was one of the factors that was imbalanced between the treatment groups at baseline, it was still fairly common in the usual care group, and continued at a steady level during follow-up. Weekly home BP monitor use in the usual care group was $13 \%$ at baseline and $16 \%$ at 6 months, while in the intervention group it was $25 \%$ at baseline and $87 \%$ at 6 months. Although the highest response category in the survey was measuring home $\mathrm{BP}$ once or more per week, it is likely that 
the weekly frequency of self-monitoring among home BP monitor users was much higher in the intervention group, given that adherence to the protocol recommendation to transmit at least six BP readings per week was high. ${ }^{17}$ Participants in the intervention group also reported greater ease in integrating home BP monitoring into their weekly routine. ${ }^{11}$

In addition, it is almost certain that such monitoring in the intervention group was more likely to have resulted in treatment changes, given participants' frequent contact with pharmacists who were charged with acting upon elevated BP measurements. A recent meta-analysis found that home BP monitoring interventions with additional support were more effective in lowering BP than monitoring without additional support. ${ }^{10}$ It was not possible to measure the effect of the improved feedback loop created by the intervention equally between the two groups, since the usual care group was not intentionally exposed to pharmacist management. In contrast, both groups continued to receive regular care from their primary care clinician and other providers, and the frequency of these contacts did not differ (unpublished data). Both groups had some increase in antihypertensive therapy during followup, but the increase was substantially greater in the intervention group, which was likely directly attributable to pharmacist-directed management. Although it might seem that DDD should be a more precise measure of treatment intensification, use of this measure did not improve the proportion of the intervention effect mediated by medication intensification. We speculate that this may have occurred because our intervention algorithm emphasized adding a new BP medication class over dose escalation for uncontrolled BP. ${ }^{12}$

Improved medication adherence was an important intended component of the intervention, but self-reported adherence was already high at baseline. Preliminary analyses among the participants for whom pharmacy claims data were available at baseline showed that the proportion of days covered measure of adherence was $>90 \%$ in both the intervention and control groups (unpublished data). ${ }^{26}$ Thus, the small contribution of improved adherence to SBP lowering might have been the result of a ceiling effect. Intervention components directed at adherence, including simplifying the medication regimen, attention to drug interactions, and responding to side effects, may have a greater effect on BP in populations with lower rates of adherence at baseline.

Although the lifestyle modification component of the intervention was enthusiastically embraced by the pharmacists, the study did not include resources for a robust behavioral intervention. Rather, interested participants were referred to existing diet, exercise, and weight management programs if they wanted more advice than was available from the pharmacists. The improved self-reported reduction in salt intake in the intervention group was encouraging, but may not have had a significant effect on BP, for several reasons. First, the selfreported reductions in salt intake in the intervention group may have simply reflected a greater awareness of the effect of dietary sodium on BP in this group compared to the usual care group, and we did not conduct any confirmatory measures of urinary sodium excretion. Second, any actual reduction in sodium intake may not have been enough to affect BP. Finally, our questionnaire asked only about salt added to food during cooking or after cooking, and the sodium content of processed foods accounts for about $75 \%$ of dietary sodium intake. ${ }^{27}$

Strengths of this analysis include prospectively collected data on a variety of mediators with a potentially large effect on $\mathrm{BP}$ in the context of a randomized trial. However, some limitations of our analysis must be kept in mind. Outcomes data on SBP were missing for about $10 \%$ of the study population, who did not attend the 6-month research clinic visit. Several of the potential mediator variables (home BP monitor use, medication adherence, salt intake, and alcohol use) were measured with categorical questionnaire responses that were difficult to translate to clinically interpretable change scores and may not have had an equal impact on SBP across the range of possible change scores. For example, for the responses to the salt intake questions, the effect on SBP of a one-point change from 5 to 4 might have been different from a change from 2 to 1 . As pharmacy claims data were not available for many of the participants, we used a relatively crude measure of self-reported adherence in these analyses. All of the lifestyle measures except weight were self-reported, which may have made it more difficult to discern intervention and mediation effects. Finally, the assumptions for linear regression and path analytic extensions (linear additive effects, independent, homoscedastic, and normal residuals, no omitted influences, normally distributed $a \cdot b$ terms, accurate measurement) are unlikely to have been met completely. ${ }^{22}$

\section{CONCLUSIONS}

About half of the intervention effect in this multifaceted trial to improve hypertension control was attributable to the combination of self-monitoring and medication intensification. This reinforces the importance of combining these two factors in successful management of uncontrolled hypertension. High medication adherence at baseline, measurement error, and the relatively low intensity of resources directed toward lifestyle change may explain why these factors did not contribute significantly to the improvement in BP. This information should be useful in the design of future interventions and implementation of similar interventions in clinical practice.

ACKNOWLEDGMENTS: The HyperLink study was funded by a grant from the National Heart, Lung, and Blood Institute (RO1 HL090965). Results included in this paper were presented at the American Heart Association Scientific Sessions 2014, Chicago, IL.

Conflict of Interest: Dr. Sperl-Hillen reports that she is a listed inventor on US patent 8,388,348 B2 titled "Disease Treatment Simulation." She is a non-paid member of the board of SiMCare Health, a company that is disseminating a provider education computer program that uses the technology under a royalty-bearing license agreement from HealthPartners. These activities are not related to the content of this manuscript. None of the other authors report potential conflicts of interest. 
Corresponding Author: Karen L. Margolis, M.D., M.P.H.; HealthPartners Institute for Education and Research, Mailstop 23301A, PO Box 1524, Minneapolis, MN 55440-1524, USA (e-mail: karen.l.margolis@healthpartners.com).

\section{REFERENCES}

1. Go AS, Mozaffarian D, Roger VL, Benjamin EJ, Berry JD, Blaha MJ, et al. Heart disease and stroke statistics-2014 update: a report from the American Heart Association. Circulation. 2014;129(3):399-410.

2. Gillespie CD, Hurvitz KA. Prevalence of hypertension and controlled hypertension - United States, 2007-2010. MMWR Surveill Summ. 2013;62(Suppl 3):144-8.

3. Go AS, Bauman MA, Coleman King SM, Fonarow GC, Lawrence W, Williams KA, et al. An effective approach to high blood pressure control: a science advisory from the American Heart Association, the American College of Cardiology, and the Centers for Disease Control and Prevention. J Am Coll Cardiol. 2014;63(12):1230-8.

4. Frieden TR, King SM, Wright JS. Protocol-based treatment of hypertension: a critical step on the pathway to progress. JAMA. 2014;311(1):21-2.

5. Walsh JM, McDonald KM, Shojania KG, Sundaram V, Nayak S, Lewis R. et al. Quality improvement strategies for hypertension management: a systematic review. Med Care. 2006;44(7):646-57.

6. Glynn LG, Murphy AW, Smith SM, Schroeder K, Fahey T. Interventions used to improve control of blood pressure in patients with hypertension. Cochrane Database Syst Rev. 2010;3, CD005182. doi:10.1002/14651858. CD005182.pub4.

7. Carter BL, Rogers M, Daly J, Zheng S, James PA. The potency of teambased care interventions for hypertension: a meta-analysis. Arch Intern Med. 2009;169(19):1748-55. doi:10.1001/archinternmed.2009.316.

8. Community Preventive Services Task F. Team-based care to improve blood pressure control: recommendation of the Community Preventive Services Task Force. Am J Prev Med. 2014;47(1):100-2. doi:10.1016/j. amepre.2014.03.003.

9. Proia KK, Thota AB, Njie GJ, Finnie RK, Hopkins DP, Mukhtar Q, et al. Team-based care and improved blood pressure control: a community guide systematic review. Am J Prev Med. 2014;47(1):86-99. doi:10.1016/j. amepre.2014.03.004.

10. Uhlig K, Patel K, Ip S, Kitsios GD, Balk EM. Self-measured blood pressure monitoring in the management of hypertension: a systematic review and meta-analysis. Ann Intern Med. 2013;159(3):185-94. doi:10. 7326/0003-4819-159-3-201308060-00008.

11. Margolis KL, Asche SE, Bergdall AR, Dehmer SP, Groen SE, Kadrmas HM, et al. Effect of home blood pressure telemonitoring and pharmacist management on blood pressure control: a cluster randomized clinical trial. JAMA. 2013;310(1):46-56. doi:10.1001/jama.2013.6549.

12. Margolis KL, Kerby TJ, Asche SE, Bergdall AR, Maciosek MV, O'Connor PJ, et al. Design and rationale for Home Blood Pressure Telemonitoring and Case Management to Control Hypertension (HyperLink): a cluster randomized trial. Control Clin Trials. 2012;33(4):794-803. doi:10.1016/j. cct.2012.03.014.

13. Chobanian AV, Bakris GL, Black HR, Cushman WC, Green LA, Izzo JL $\mathbf{J r}$, et al. The seventh report of the joint national committee on prevention, detection, evaluation, and treatment of high blood pressure: the JNC 7 report. JAMA. 2003;289(19):2560-72. doi:10.1001/jama.289.19.2560.

14. Centers for Medicare \& Medicaid Services. 2012 Medicare Part D Medication Therapy Management (MTM) Programs. http://www.cms.gov/Medicare/ Prescription-Drug-Coverage/PrescriptionDrugCovContra/Downloads / CY2012-MTM-Fact-Sheet.pdf. Accessed 04/02/2015.

15. Pickering T. Recommendations for the use of home (self) and ambulatory blood pressure monitoring. American Society of Hypertension Ad Hoc Panel. Am J Hypertens. 1996;9(1):1-11.

16. Staessen JA, Den Hond E, Celis H, Fagard R, Keary L, Vandenhoven G, et al. Antihypertensive treatment based on blood pressure measurement at home or in the physician's office: a randomized controlled trial. JAMA. 2004;291(8):955-64. doi:10.1001/jama.291.8.955.

17. Kerby TJ, Asche SE, Maciosek MV, O'Connor PJ, Sperl-Hillen JM, Margolis KL. Adherence to blood pressure telemonitoring in a clusterrandomized clinical trial. J Clin Hypertens (Greenwich). 2012;14(10):66874. doi:10.1111/j.1751-7176.2012.00685.x.

18. Ralston JD, Cook AJ, Anderson ML, Catz SL, Fishman PA, Carlson J, et al. Home blood pressure monitoring, secure electronic messaging and medication intensification for improving hypertension control: a mediation analysis. Appl Clin Inform. 2014;5(1):232-48. doi:10.4338/aci-2013-10ra-0079.

19. Morisky DE, Green LW, Levine DM. Concurrent and predictive validity of a self-reported measure of medication adherence. Med Care. 1986;24(1):67-74.

20. Wessling A, Boethius G. Measurement of drug use in a defined population. Evaluation of the defined daily dose (DDD) methodology. Eur J Clin Pharmacol. 1990;39(3):207-10.

21. World Health Organization. Collaborating Centre for Drug Statistics Methodology. Definition and general considerations. http://www.whocc. no/ddd/definition_and_general_considera/. Accessed 04/02/2015.

22. MacKinnon DP. Introduction to Statistical Mediation Analysis. New York: Erlbaum; 2008.

23. Baron RM, Kenny DA. The moderator-mediator variable distinction in social psychological research: conceptual, strategic, and statistical considerations. J Pers Soc Psychol. 1986;51(6):1173-82.

24. Muthen LK, Muthen BO. Mplus User's Guide. 6th ed. Los Angeles, CA: Muthen \& Muthen; 2010.

25. Green BB, Cook AJ, Ralston JD, Fishman PA, Catz SL, Carlson J, et al. Effectiveness of home blood pressure monitoring, Web communication, and pharmacist care on hypertension control: a randomized controlled trial. JAMA. 2008;299(24):2857-67. doi:10.1001/jama.299.24.2857.

26. Hess LM, Raebel MA, Conner DA, Malone DC. Measurement of adherence in pharmacy administrative databases: a proposal for standard definitions and preferred measures. Ann Pharmacother. 2006;40(78): 1280-8. doi:10.1345/aph.1H018.

27. CDC. GET THE FACTS: Sources of Sodium in Your Diet. http://www.cdc. gov/salt/pdfs/sources_of_sodium.pdf. Accessed 04/02/2015. 